\title{
Epizootic and epidemiological situation of Trichinella sp. infection in Poland in 2006-2015 in view of wild boar population dynamics
}

\author{
Marian Flis $^{1}$, Eugeniusz R. Grela ${ }^{2}$, Dariusz Gugała ${ }^{1}$ \\ ${ }^{1}$ Department of Zoology, Ecology and Wildlife Management, \\ ${ }^{2}$ Institute of Animal Nutrition and Bromatology, \\ Faculty of Biology, Animal Sciences and Bioeconomy, \\ University of Life Sciences in Lublin, 20-950 Lublin, Poland \\ marian.flis@up.lublin.pl
}

Received: December 9, 2016 Accepted: May 10, 2017

\begin{abstract}
Introduction: The objective was to evaluate the epizootic and epidemiological situation of Trichinella sp. infection in Poland between 2006 and 2015 against the dynamics of the wild boar population and its primary reservoir host. Material and Methods: Boar and porcine trichinosis epizootic analysis was based on General Veterinary Inspectorate data from RRW-6 bulletins. The epidemiological situation was evaluated on the basis of the data supplied by the Department of Epidemiology of the National Institute of Hygiene - National Institute of Public Health. The wild boar hunting harvest and population dynamics were estimated, as these animals remain the basic infection source for humans. Population size and harvest data were obtained from hunting statistics. Results: The study timeframe showed an almost 2.5 -fold increase in Trichinella infection cases in wild boars but a significant decline in human cases. In the domestic pig, the incidence rate did not exceed $0.00037 \%$. The highest infection risk exists in West Pomerania, Greater Poland, and Kuyavian-Pomeranian Provinces. Over the study period, the wild boar population increased more than 1.5-fold, while the hunting harvest more than tripled. During the last two seasons the total hunt surpassed $100 \%$ of the spring population. Conclusion: Wild boar management by increasing the hunting take of the annual population growth should limit that growth and decrease the take in the future. Thereby, over some years intra-species trichinosis spread should reduce, for a substantial safety gain for wild boar meat.
\end{abstract}

Keywords: wild boar, Trichinella, epidemiology, Poland.

\section{Introduction}

Trichinosis (trichinellosis) is one of the most common parasitic zoonoses with a complex epizootiologic process and it still remains an important epidemiological problem in Poland, other European countries, and throughout much of the world $(1,2,4$, $17-19,23,26)$. The first reports of a disease whose clinical symptoms bear some resemblance to trichinosis date back to 422 B.C., when during the war between Carthage and Sicily an epidemic outbreak of the disease among the Carthaginians is thought to have directly affected the result of the conflict. The disease was recognised as a clinical entity in 1863. A massive increase of trichinosis occurred after the Second World War, and by the early 1960s the annual number of cases of the illness ranged from about 200 to more than
2,000. In addition, there were epidemiological outbreaks of trichinosis with a large number of infected individuals, simultaneously; however, the intensity was relatively low. At the turn of the $20^{\text {th }}$ and $21^{\text {st }}$ centuries a decrease in morbidity has occurred, although there have been a few outbreaks of the disease, mainly in the western part of Poland $(6,15,28)$.

Trichinellosis is caused by polyxenous internal parasites (Nematoda, Trichinellidae sp.) with welldeveloped ability to colonise and grow inside a wide range of hosts. The predominant species belongs to a small group of nematodes whose larvae and mature individuals complete all stages of development within one host. The last decades have been marked by substantial changes in the epizootic and epidemiological picture of the disease, i.e. new Trichinella species pathogenic for humans have been 
identified (27). Currently, 9 species and 12 genotypes of Trichinella are recognised (13), and among them Trichinella spiralis is the predominant one. The distribution area of the parasite has also expanded over the decades and the typical reservoirs for infectious agents have also undergone specific modifications. As Trichinella sp. occurs in sylvatic and synanthropic environments, it can be harboured by wild and domestic species and therefore, this highly adaptive parasite is one of the most ubiquitous parasitic nematodes. Presently, approximately 250 animal species have been found to be reservoir hosts of the parasite $(2,6,11,13,21,28,29)$.

Being so widely distributed, this zoonosis represents a serious and constant epidemiological problem. Originating in wildlife species, it can be well established in domestic animals, mainly pigs but occasionally horses, and may become so in humans. Wild boars and predators, chiefly foxes, are known to constitute the major source of Trichinella in wildlife in Poland. The primary natural reservoir of the parasite is wild boar. Observable in recent years is the increasing number of wild boar populations, requiring a larger cull, and thus putting a greater supply of wild boar meat into the market. Therefore, permanent monitoring of the presence of trichinosis in wild boar meat is essential for food safety, in this case safety of game meat. Considering the aforementioned epizootic situation, it is crucial to examine each boar for the presence of Trichinella, by implementing the "etching" method $(2,8,13,25,26)$.

Other species of Trichinella also have zoonotic importance, e.g. Trichinella pseudospiralis has been recognised recently in sylvatic habitats, predominantly in foxes in Poland and other countries $(12,22)$. In Poland, the parasite was recovered for the first time from a wild boar which was harvested in the Pomeranian region (3). The detection of Trichinella pseudospiralis is challenging as it is the only species identified in Europe with non-encapsulated larvae in host muscle tissue, and so it requires implementation of the artificial digestion assay and is not detected through the use of the compression method (12).

The aim of the study was to recognise the occurrence of trichinosis among wild and domestic animals in the country during the 2015-2016 period in terms of population strength and hunting take dynamics of boars, regarding the epizootic threat and food safety of the marketed game meat.

\section{Material and Methods}

The analysis of trichinosis in wild boars and pigs, a practical study of the current epizootic situation in Poland, was based on data provided by the General Veterinary Inspectorate and obtained from the Veterinary Inspection RRW-6 bulletins. The records obtained from the detailed reports on the prevalence of infectious diseases and food poisoning in Poland were tabulated and presented graphically to illustrate trichinellosis in domestic pigs and wild boars. The epidemiological situation was evaluated on the basis of the data from the reports supplied by the Department of Epidemiology of the National Institute of Hygiene National Institute of Public Health. Trichinosis in wild boars and humans was presented in its geographic distribution via the epizootic and epidemiological maps developed for particular provinces. The dynamics of wild boar population size and hunting harvest of the animals were also estimated as these animals remain the basic infection source for humans. The data related to the population size and hunting harvest were obtained from the hunting statistics. Calculation of the obtained results was made using a Microsoft Excel spreadsheet.

\section{Results}

During the ten-year study period (2006-2015), trichinellosis was recognised in 282 pigs (Table 1). The largest numbers of confirmed presences of Trichinella in muscle tissue samples were recorded in 2007, 2008, and 2013 , and they were 51,69 , and 78 respectively. In other years, the number of trichinellosis cases diagnosed annually was markedly lower and ranged between 3 and 28. These values as a percentage of the number of examined specimens indicate the low infection rate in pork, from $0.00001 \%$ up to $0.00037 \%$. During the same time, 5203 trichinosis cases were reported in wild boar. Throughout the study period, the Trichinella detection rate in the wild boar meat samples displayed a noticeable upward trend $(\mathrm{y}=38.745 \mathrm{x}+$ $307.2, \mathrm{R}^{2}=0.7096$ ), despite substantial fluctuations between the years. The high and significant determination coefficient indicates a predictable further increase in trichinellosis incidence in the discussed animal species. The number of cases recognised each year in relation to the number of specimens examined places the infection rate within the $0.29 \%-1.09 \%$ interval. During the ten-year study, Trichinella sp. was identified on average in one out of every 195 specimens examined.

The spatial distribution of the Trichinella cases recognised in wild boars in the last decade indicates high differentiation in its occurrence between provinces (Fig. 1). As illustrated in the trichinellosis epizootic risk map, the highest number of cases occurred in the West Pomeranian Province where Trichinella sp. was recovered in 100 wild boar carcasses per year, and the second highest in the Kuyavian-Pomeranian Province with 933 confirmed trichinosis cases. An annual average of over 60 Trichinella cases per year in wild boar meat specimens was stated in the Pomeranian and Greater Poland Provinces. The smallest number of cases was detected in the Silesian, Opole, Podlasie, and Mazovian Provinces, with 36, 54, 93, and 96 cases per year. 
Table 1. Trichinosis in pigs and wild boars in Poland between 2006 and 2015*

\begin{tabular}{|c|c|c|c|c|c|c|}
\hline \multirow{2}{*}{$\begin{array}{l}\text { Research } \\
\text { period }\end{array}$} & \multicolumn{3}{|c|}{ Pigs } & \multicolumn{3}{|c|}{ Wild boars } \\
\hline & examined & positive & $\%$ & examined & positive & $\%$ \\
\hline 2006 & $21,985,532$ & 28 & 0.00013 & 78,650 & 321 & 0.41 \\
\hline 2007 & $23,015,105$ & 51 & 0.00022 & 103,305 & 296 & 0.29 \\
\hline 2008 & $20,027,092$ & 69 & 0.00034 & 103,612 & 522 & 0.5 \\
\hline 2009 & $17,799,002$ & 14 & 0.00008 & 50,433 & 552 & 1.09 \\
\hline 2010 & $19,730,521$ & 12 & 0.00006 & 87,614 & 558 & 0.64 \\
\hline 2011 & $20,394,971$ & 8 & 0.00004 & 86,940 & 465 & 0.53 \\
\hline 2012 & $19,886,796$ & 11 & 0.00006 & 108,605 & 481 & 0.44 \\
\hline 2013 & $20,949,761$ & 78 & 0.00037 & 118,380 & 645 & 0.54 \\
\hline 2014 & $21,551,492$ & 3 & 0.00001 & 141,617 & 611 & 0.43 \\
\hline 2015 & $21,973,398$ & 8 & 0.00004 & 132,865 & 752 & 0.51 \\
\hline In total & $207,313,670$ & 282 & 0.00014 & $1,012,021$ & 5,203 & 0.51 \\
\hline
\end{tabular}

* - the table does not include data from the economic slaughter

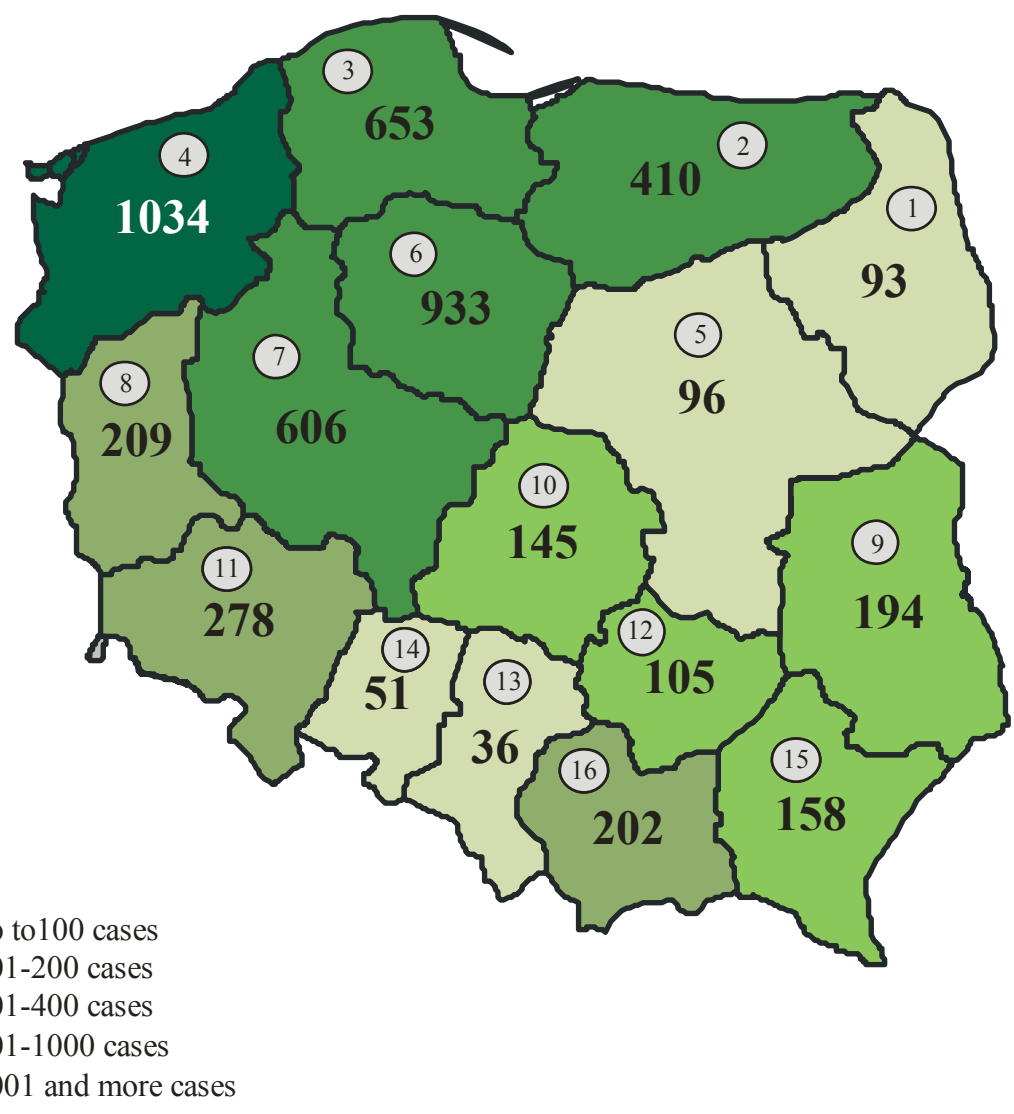

Fig. 1. The number of ascertained cases of trichinosis in wild boars in Poland between 2006 and 2015, 1 - Podlasie Province, 2 - Warmian-Masurian Province, 3 - Pomeranian Province, 4 - West Pomeranian Province, 5 - Masovian Province, 6 - Kuyavian-Pomeranian Province, 7 - Greater Poland Province, 8 - Lubuskie Province, 9 - Lublin Province, 10 - Łódź Province, 11 - Lower Silesian Province, 12 - Holy Cross Province, 13 - Silesian Province, 14 - Opole Province, 15 - Subcarpathian Province, 16 - Lesser Poland Province 
The presented trichinosis epizootic situation in animals considered the major infection source did not significantly affect the epidemiological situation (Fig. 2) as at this period, the trichinellosis incidence rate declined considerably $\left(\mathrm{y}=-17.303 \mathrm{x}+155.67, \mathrm{R}^{2}=\right.$ 0.3438). Throughout the study period, 605 trichinosis cases were diagnosed in humans.

The spatial distribution of human trichinellosis points out that people in the West Pomeranian, Greater Poland, and Kuyavian Provinces are at the highest risk for exposure to infection. Notably, in these regions combined $77 \%$ of all human infections were recorded. During the studied period, four provinces were free from trichinellosis, whereas in the southern and eastern parts of Poland along with the Opole region two to six cases were found (Fig. 3).

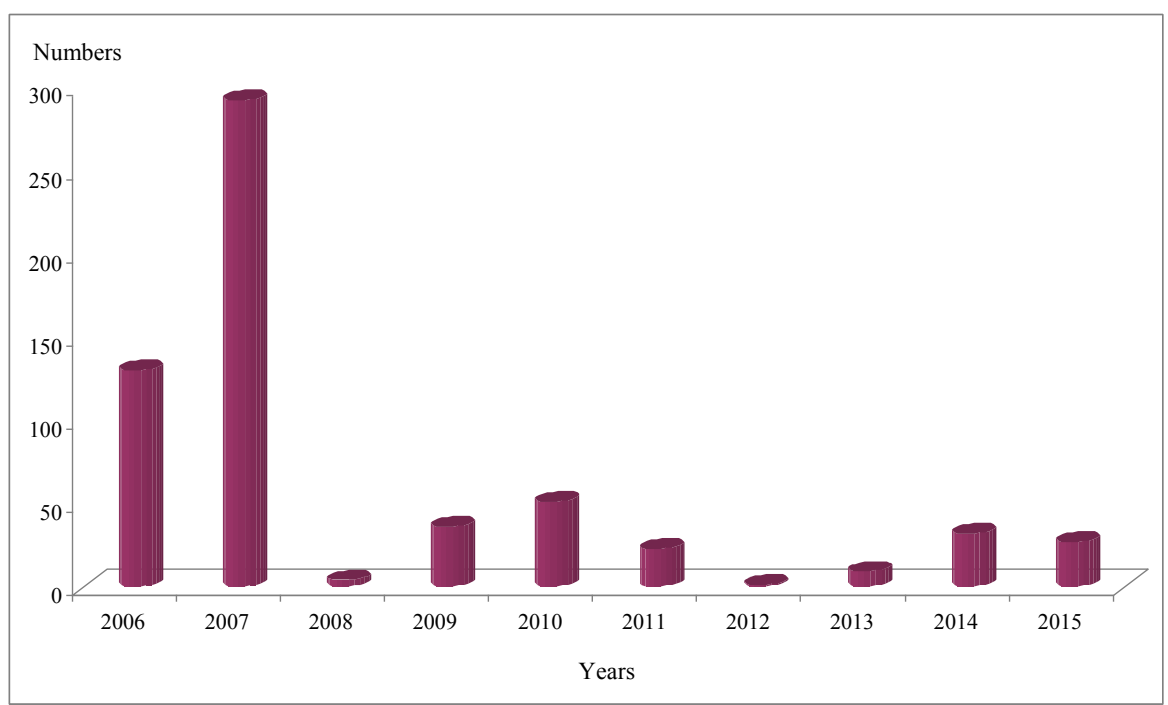

Fig. 2. The number of trichinosis cases among people in Poland between 2006 and 2015
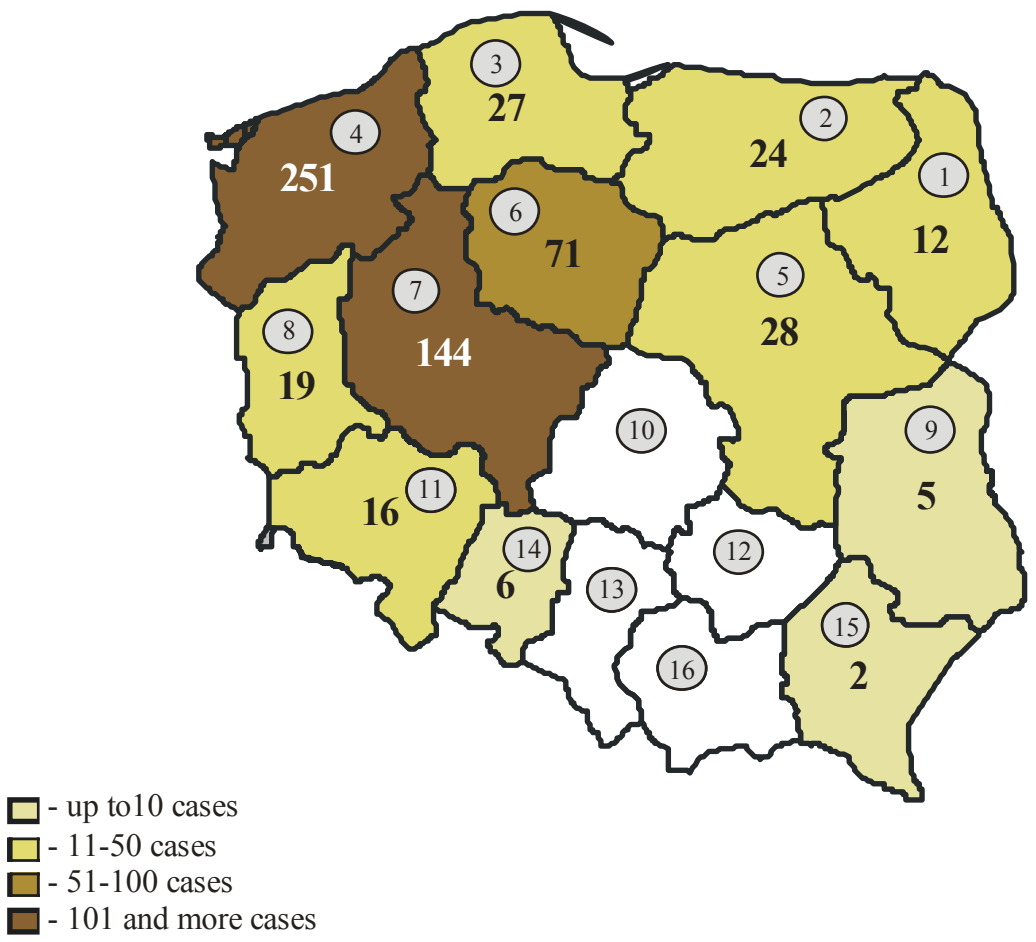

Fig. 3. The number of trichinosis cases in humans in Poland between 2006 and 2015, 1 Podlasie Province, 2 - Warmian-Masurian Province, 3 - Pomeranian Province, 4 - West Pomeranian Province, 5 - Masovian Province, 6 - Kuyavian-Pomeranian Province, 7 Greater Poland Province, 8 - Lubuskie Province, 9 - Lublin Province, 10 - Łódź Province, 11 - Lower Silesian Province, 12 - Holy Cross Province, 13 - Silesian Province, 14 - Opole Province, 15 - Subcarpathian Province, 16 - Lesser Poland Province 


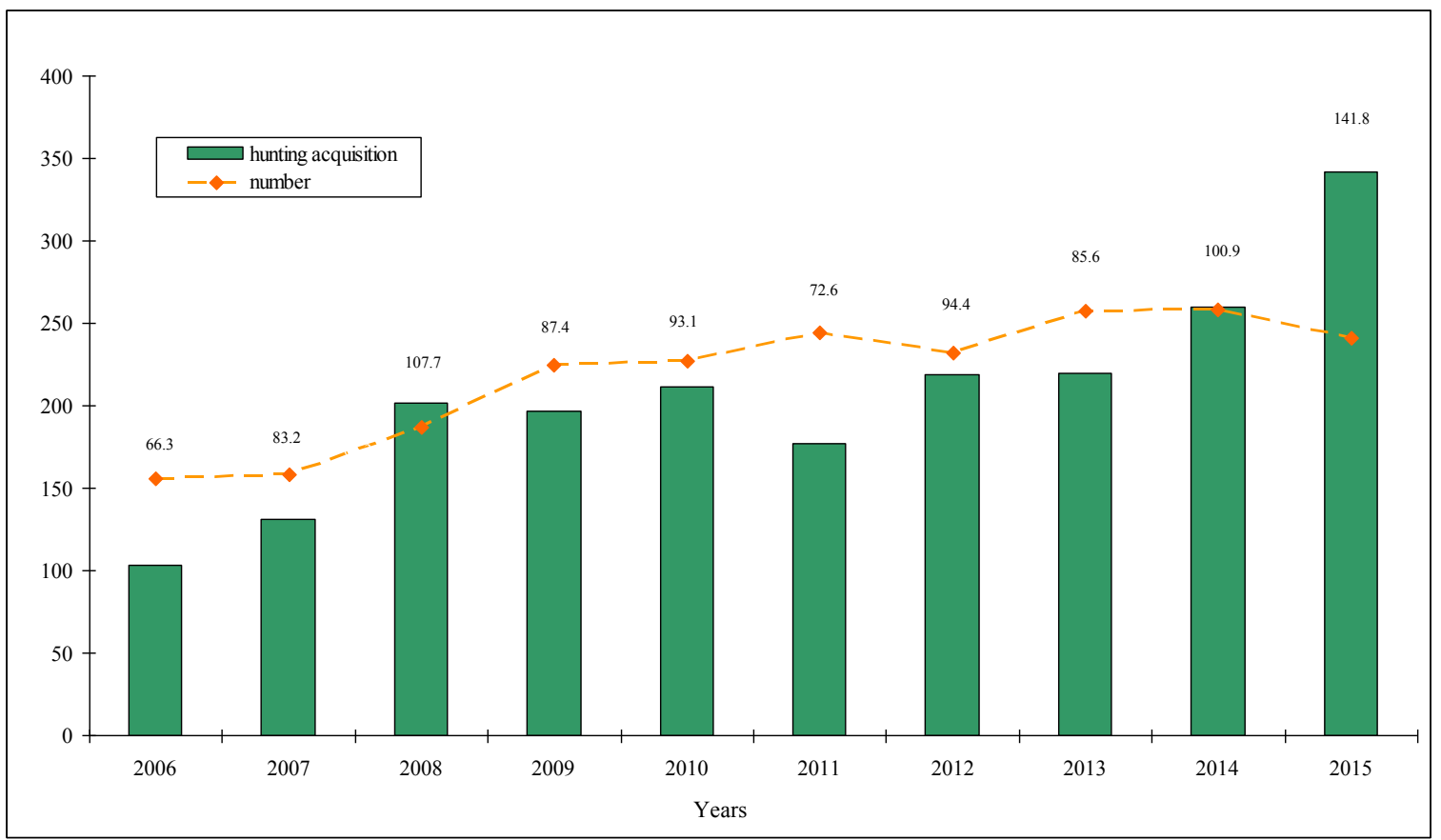

Fig. 4. The number of wild boars and hunting acquisition (thousand individuals) by the Polish Hunting Association

In the last decade, the wild boar population has increased by over half in the hunting zones leased by the Polish Hunting Association, which account for about $95 \%$ of all hunting areas in Poland (Fig. 4). The estimated value of the trend line equation and the high and significant coefficient of determination confirm the current, and it cannot be ruled out, future directions of the population trend of this species $\left(y=9.9127 x+162.01, R^{2}=0.7704\right)$. The progressing population growth was associated with an observable annual increase in the hunting harvest taken through shooting $\left(y=19.234 x+100.45 ; R^{2}=0.7859\right)$. In turn, the hunting exploitation level illustrating the actual harvest and hunting pressure on the population was found within the $66.3 \%-141.8 \%$ interval. The over $100 \%$ level noted in the last two years allows an optimistic prediction about the appropriateness of the direction of hunting policy, given that it aims for a radical reduction of wild boar numbers.

\section{Discussion}

The over 4,500 times higher frequency of trichinellosis detection in wild boar meat samples than in domestic pig samples supports the thesis that wild boars still remain the natural reservoir of the parasite. They have been documented as representing an epidemiological risk factor in Poland and abroad (7, 14, 16, 17, 20). Although Trichinella is also identified in other wild animals, especially predators, considering the alimentary mode of infection, it does not constitute a direct threat to humans from these animals. However, it is worth mentioning that an indirect threat exists because of Trichinella transmission from the domestic stock environment to natural habitats and vice versa. Notably, most frequently it is the result of inappropriate husbandry practices that do not comply with zoohygiene regulations $(1,2,7,14,16,20,25)$. What should also be taken into account is that trichinosis can occur in other species of wild and domestic animals, in such herbivores as beavers whose meat is edible and thus are a potential source of parasite transmission (29).

The current intensity of trichinellosis incidence in wild boars has markedly increased from that of the $1980 \mathrm{~s}$ and 1990s. At the turn of the eighties, the primary source of human infection was pork, which accounted for as many as $70 \%$ of total cases. At that time, wild boar meat constituted only around $23 \%$ of infections. In the period 1996-2001, the rate of Trichinella infection in wild boar meat specimens was shown to range from $0.18 \%$ up to $0.31 \%$ and was lower by over half as against the previous decade. During 2000-2005, Trichinella detected in wild boar meat was the cause of human trichinellosis in $88 \%$ of cases $(5,15)$.

The epidemiological situation in the past decade does not reflect the growing number of trichinosis cases recognised in wild boars. It merely means that the public attitude to mandating the inspection of wild boar meat intended for human consumption has changed in favour of safety. However, as the current management plan for this species population is focused on growing the annual harvest, which is imposed by the population dynamics, trichinellosis is still a serious public health threat. Importantly, the rise in the hunting harvest is also associated with 
a greater epizootic risk for African swine fever as well as more numerous compensation payments for crop and field damage which have to be paid by the leaseholders of the hunting zones. The growing interest of hunters in the meat of wild boars for personal use leads to the broader distribution of game originating from the species, particularly among families, friends, households etc. - as snacks. Consequently, the absence of relevant medical testing may increase the epidemiological risk $(7,9,10,24)$.

The research results for the trichinellosis epizootic situation in Poland indicate that the last decade was marked with a substantial increase in the Trichinella infection rate in wild boars. Specifically, on average 156 cases of trichinellosis have been detected annually. During this time, the number of trichinosis cases recognised in pigs maintained a similar level, i.e. it did not exceed $0.00037 \%$ of the carcasses tested, while the incidence rate of human trichinellosis declined. The West Pomeranian, Greater Poland, and Kuyavian Provinces are the regions of the highest prevalence of Trichinella in wild boars, which is reflected in the human prevalence rate in these regions. The Silesian, Opole, Mazovian, and Podlasie regions are the areas of the lowest trichinosis prevalence in wild boars. During the evaluation of the epizootic and epidemiological situation of Trichinella, a dynamic increase in the wild boar population was noted along with an enlarging hunting harvest of these animals. This status in conjunction with wildlife game gaining popularity among hunters is likely to lead to an elevated epidemiological risk. Taking into account the epizootic situation presented above, every harvested wild boar should be tested for Trichinella. Special emphasis should be placed on the nonencapsulating species Trichinella pseudospiralis as it has recently been detected more commonly in wild boars. Therefore, the digestion assay for the detection of Trichinella larvae in meat samples is a recommended test method for effective Trichinella diagnosis and control.

Conflict of Interests Statement: The authors declare that there is no conflict of interests regarding the publication of this article.

Financial Disclosure Statement: The research and the article were funded by the University of Life Sciences in Lublin.

Animal Rights Statement: None required.

\section{References}

1. Aoun O., Lacour S.A., Levieuge A., Marié J.L., Vallée I., Davoust B.: Screening for Trichinella britovi infection in red fox (Vulpes vulpes) and wild boar (Sus scrofa) in Southeastern France. J Wildl Dis 2012, 48, 223-225.
2. Bilska-Zając E., Różycki M., Chmurzyńska E., Osek J.: Occurrence of trichinellosis in animals and humans in European Union countries and countries neighbouring Poland. Życie Weter 2001, 86, 307-311.

3. Bilska-Zając E., Różycki M., Chmurzyńska E., Karamon J., Sroka J., Antolak E., Próchniak M., Cencek T.: First record of wild boar infected with Trichinella pseudospiralis in Poland. J Vet Res 2016, 60, 147-152.

4. Britov V.A.: Trichinosis in Kamchatka. Wiad Parazytol 1997, 43, 287-288.

5. Cabaj W., Moskwa B., Pastusiak K., Malczewski A.: Trichinellosis in wild animals and domestic pigs in Poland. Med Weter 2004, 60, 80-83.

6. Cabaj W.: Wild and domestic animals as permanent Trichinella reservoir in Poland. Wiad Parazyt 2006, 52, 175-179.

7. Flis M.: Incidence of trichinosis in wild boars and swine in Poland in 2003-2009. Med Weter 2011, 67, 470-473.

8. Flis M.: Wild boar population management vs. damage conditions in economical and social grasps. Ann Warsaw Univ Life Sci - SGGW 2011, 50, 43-50.

9. Flis M.: The problem of game damage in terms of land ownership, hunting rights, and environmental determinants. Przegl Hod 2016, 2, 28-29.

10. Flis M.: Game as a food source - legal and economic aspects of its introduction to the market. Przegl Hod 2016, 6, 29-31.

11. Gawor J.: Trichinellosis in wild boars and wild carnivores as growing threat for human infection in Poland. Życie Weter 2011, 86, 806-809.

12. Gawor J.: Trichinella pseudospiralis - a new species of Trichinella in sylvatic cycle in Poland. Does the treat of trichinellosis in humans increase? Życie Weter 2013, 88, 1053-1054

13. Gliński Z.: Zoonotic diseases of game animals. Part I. Trichinellosis, rabies, tularemia, borelliosis. Życie Weter 2016, $91,560-564$.

14. Gołąb E., Sadkowska-Todys M.: Nowadays problems of epidemiology and diagnosis of trichinosis in the European Union and in Poland. Przegl Epidem 2003, 57, 561-570.

15. Gołąb E., Sadkowska-Todys M.: Epidemiology of human trichinellosis in Poland - currently and in the past. Wiad Parazyt 2006, 52, 181-187.

16. Gottstein B., Pozio E., Nöckler K.: Epidemiology, diagnosis, treatment, and control of trichinellosis. Clin Microbiol Rev 2009, 22, 127-145.

17. Holzbauer, S., Agger, W., Hall W.A., Johnson G.M., Schmitt D., Garvey A., Bishop H.S., Rivera H., de Almeida M.E., Hill D., Stromberg B.E., Lynfield R., Smth K.E.: Outbreak of Trichinella spiralis infections associated with a wild boar hunted at a game farm in Iowa. Clin Infect Dis 2014, 59, 12, 1750-1756.

18. Hurnikowá Z., Dubinský P.: Long-term survey on Trichinella prevalence in wildlife of Slovakia. Vet Parasitol 2009, 159, 276-280.

19. Jongwutiwes S., Chantachum N., Kraivichian P., Siriyasatien P., Putaporntip C., Tamburrini A.: First outbreak of human trichinellosis caused by Trichinella pseudospiralis. Clin Infect Dis 1998, 26, 111-115.

20. Kirjušina M., Deksne G., Marucci G., Bakasejevs E., Jahundoviča I., Daukšte A., Zdankovska A., Bērziņa Z., Esīte Z., Bella A., Galati F., Krūmiṇa A., Pozio E.: A 38 -year study on Trichinella spp. in wild boar (Sus scrofa) of Latvia shows a stable incidence with an increased parasite biomass in the last decade. Parasit Vect 2015, 8, 137

21. McIntyre, L., Pollock S.L., Fyfe M., Gajadhar A., IsaacRenton J., Fung J., Morshed M.: Trichinellosis from consumption of wild game meat. Can Med Assoc J 2007, 176, 4, 449-451.

22. Moskwa B., Goździk K., Bień J., Borecka A., Gawor J., Cabaj W.: First report of Trichinella pseudospiralis in Poland, in red foxes (Vulpes vulpes). Acta Parasitol 2013, 58, 149-154. 
23. Murrell K.D., Pozio E.: Trichinellosis: the zoonosis that won't go quietly. Inter J Parasitol 2000, 30, 1339-1349.

24. Popczyk B.: Zarządzanie populacją dzika Sus scrofa w Polsce. In: Zarządzanie populacjami zwierzat. Editor - Polish Hunting Union, Łowiec Polski, Warszawa 2016, pp. 29-45.

25. Pozio E., Gomez Morales M.A., Dupouy-Camet J.: Clinical aspects, diagnosis and treatment of trichinellosis. Expert Rev Anti Infect Ther 2003, 1, 471-482.

26. Pozio E., Rinaldi L., Maruccia G., Musellac V., Galatid F., Cringolib G., Boireaue P., La Rosaa G.: Hosts and habitat of
Trichinella spiralis and Trichinella britovi in Europe. Int J Parasit 2009, 39, 71-79.

27. Pozio E., Zarlenga D.S.: New species of the Trichinella puzzle. Int J Parasitol 2013, 43, 983-997.

28. Różycki M., Kubica M., Bilska-Zając E., Chmurzyńska E., Karamon J., Cencek T.: Trichinosis in North-Western part of Poland. Is the parasitosis evading control? Życie Weter 2016, 91, 364-368.

29. Seglina Z., Bakasejevs E., Deksne G., Spungis V., Kurjušina M.: New finding of Trichinella britovi in a European beaver (Castor fiber) in Latvia. Parasitol Res 2015, 114, 3171-3173. 